\title{
Effects of In Vivo Hepatic Ischemia-Reperfusion Injury on the Hepatobiliary Disposition of Rhodamine 123 and its Metabolites in Isolated Perfused Rat Livers
}

\author{
Ridhi Parasrampuria, Imam H. Shaik, Reza Mehvar. \\ Department of Pharmaceutical Sciences, School of Pharmacy, Texas Tech University Health Sciences Center, Amarillo, \\ Texas, USA.
}

Received, April 4, 2012; Accepted, April 26, 2012; Published, April 26, 2012.

\begin{abstract}
Purpose. A few studies have shown that normothermic hepatic ischemia-reperfusion (IR) injury may affect the mRNA and/or protein levels of canalicular transporters P-glycoprotein (P-gp) and multidrug resistance-associated protein 2 (Mrp2). However, the effects of the injury on the functions of these canalicular transporters with respect to the biliary excretion of drugs remain largely unknown. Therefore, the purpose of this study was to investigate the effects of warm hepatic IR on the hepatobiliary disposition of rhodamine 123 (RH123), a P-gp substrate, and its glucuronidated metabolite (RH-Glu), an Mrp2 substrate, in rats. Methods. Twenty four or $72 \mathrm{~h}$ following a 60 -min partial ischemia or sham operation in rats, livers were isolated and perfused ex vivo with a constant concentration $(\sim 100 \mathrm{ng} / \mathrm{mL})$ of RH-123. The concentration of RH-123 and its glucuronidated (RH-Glu) and deacylated (RH-110) metabolites were determined in the outlet perfusate, bile, and the liver tissue using HPLC, and relevant pharmacokinetic parameters were estimated. Results. Twentyfour-h IR caused a significant reduction in the hepatic extraction ratio of RH-123 (IR: $0.857 \pm 0.078$; Sham: $0.980 \pm 0.017)$ and the biliary recovery of the parent drug and RH-Glu by $43 \%$ and $44 \%$, respectively. The reductions in the biliary recovery were associated with significant reductions in the apparent biliary clearance of RH-123 and RH-Glu. Mass balance data showed that the formation of the glucuronidated or deacylated metabolite was not significantly affected by the 24-h IR injury. In contrast to the 24-h IR, the injury did not have any effect on the hepatobiliary disposition of RH-123 or its metabolites following $72 \mathrm{~h}$ of reperfusion. Conclusions. It is concluded that the pharmacokinetics of drugs that are subject to biliary excretion by the canalicular P-gp and Mrp2 transporters may be altered shortly after hepatic IR injury.
\end{abstract}

This article is open to POST-PUBLICATION REVIEW. Registered readers (see "For Readers") may comment by clicking on ABSTRACT on the issue's contents page.

\section{INTRODUCTION}

Warm hepatic ischemia-reperfusion (IR) injury is a serious complication of many clinical situations, such as hepatic resection surgery, hemorrhagic and septic shock, and liver transplantation (1-3). Numerous factors, such as the release of reactive oxygen species (ROS) and proinflammatory cytokines, have been reported to be involved in the pathophysiology of hepatic IR injury (4). Previous studies have shown that the inflammatory processes resulting in the release of cytokines may alter the expression of hepatic transporters $(5,6)$. Therefore, it is likely that the expression and function of these transporters are altered after the liver IR injury. Indeed, the limited data available in the literature (7-10) suggest that the mRNA and protein levels of the canalicular transporters P-glycoprotein (P-gp) and multidrug resistance-associated protein 2 (Mrp2) may be altered by warm hepatic IR injury. However, the effects of the injury on the functions of these canalicular transporters with respect to the biliary excretion of drugs remain largely unknown. This is important because the functional changes in the activity of proteins do not always correlate with the changes in their mRNA or protein levels (11). Therefore, it is necessary to investigate the changes in the activity of liver transporters after hepatic IR injury.

\footnotetext{
Corresponding Author: Reza Mehvar, Ph.D., School of Pharmacy, Texas Tech University Health Sciences Center, 1300 Coulter, Amarillo, TX 79106, USA;

Email: reza.mehvar@ttuhsc.edu
} 
The cationic dye rhodamine 123 (RH-123) is a P-gp substrate, which has been used extensively as a marker of P-gp activity in vitro in cells, ex vivo in isolated organs, and in vivo in whole animals. We have recently (12) characterized the hepatobiliary disposition of RH-123 in an isolated perfused liver (IPRL) model and showed that the biliary excretion of the dye is reduced after pharmacological inhibition of P-gp activity (13). Additionally, it was shown that the biliary clearance of the glucuronidated metabolite of the dye (RH-Glu) is sensitive to the modulation of Mrp2 activity (13). Based on these observations, it was suggested that RH-123 may serve as a dual marker for the functions of both P-gp and Mrp2 in the IPRL model via simultaneous monitoring of the biliary clearances of the parent drug and the generated glucuronide metabolite, respectively (13). Therefore, we selected RH-123 as a marker for our functional studies in the present study.

Previous studies have shown that the hepatic IR injury is associated with injury to remote organs, such as the lungs $(14,15)$ and kidneys $(16,17)$. This may complicate the delineation of the effects of hepatic IR on the canalicular efflux transporters after in vivo administration of RH-123. To avoid these confounding effects, we chose to determine the hepatobiliary disposition of RH-123 and its metabolites ex vivo in livers isolated from the animals that underwent in vivo IR injury. Earlier reports suggested a significant downregulation of mRNA (10) and protein (8) levels of Mrp2 in the liver as a result of hepatic IR. However, the mRNA (Mdr1b) (10) and protein (7) levels of P-gp were upregulated after the injury. Therefore, we hypothesized that whereas hepatic IR injury would increase the biliary transport of RH-123, the biliary excretion of its glucuronidated metabolite would be reduced by the injury.

\section{MATERIAL AND METHODS}

\section{Chemicals and reagents}

RH-123 was obtained from MP Biomedicals (Solon, OH, USA). Rhodamine-110 (RH-110) and $\beta$-glucuronidase (TYPE -LII) were purchased from Sigma Chemicals Co. (St. Louis, MO, USA). For anesthesia, ketamine and xylazine solutions were purchased from Lloyd Laboratories (Shenandoah, IA, USA) and Fort Dodge Animal Health (Fort Dodge, IA, USA), respectively. Kits for measurement of alanine aminotransferase (ALT) were purchased from Teco Diagnostics (Anaheim, CA, USA). All other reagents were of analytical grade and obtained from commercial sources.

\section{Animals}

The procedures involving animals were approved by the Texas Tech University Health Sciences Center Animal Care and Use Committee and were consistent with the guidelines set by the National Institutes of Health (NIH publication \#85-23, revised 1985).

Adult (225-275 g), male Sprague-Dawley rats were purchased from Charles River Laboratories, Inc. (Wilmington, MA, USA). All animals were maintained on a 12-h light/dark cycle with free access to food and water before the experiments.

Experimental groups and partial hepatic ischemia-reperfusion surgery

A total of 28 rats underwent $1 \mathrm{~h}$ of partial $(70 \%)$ ischemia (IR) or sham operation (Sham), followed by 24 or $72 \mathrm{~h}$ of in vivo reperfusion, resulting in four groups of Sham-24 $(n=8)$, IR-24 $(n=8)$, Sham$72(n=6)$, and IR-72 $(n=6)$.

The surgical procedures for IR were similar to those described before $(18,19)$. Briefly, after an overnight fast, animals were anesthetized by an intramuscular administration of ketamine: xylazine $(80: 10 \mathrm{mg} / \mathrm{kg}$ body weight). Partial ischemia was then induced by clamping those branches of the portal vein, hepatic artery, and bile duct that supply the left and median lobes of the liver, leaving the perfusion to the right and caudate lobes uninterrupted. During ischemia, temperature of the rat was closely monitored and maintained at $37^{\circ} \mathrm{C}$ using a combination of a heating lamp and a heating plate. After $60 \mathrm{~min}$ of partial ischemia, the clamp was removed to allow reperfusion. Subsequently, 5 $\mathrm{mL}$ of sterile saline $\left(37^{\circ} \mathrm{C}\right)$ was added to the peritoneal cavity to compensate for any volume loss during the surgery before closure of the abdomen. Sham-operated animals underwent the same surgical procedure without clamping.

\section{Isolation and ex vivo perfusion of livers with RH- 123}

After 24 or $72 \mathrm{~h}$ in vivo reperfusion, livers were cannulated, harvested, and perfused ex vivo for 60 min by the method outlined by us in details earlier $(20,21)$. The perfusion was conducted in a water- 
jacketed glass perfusion system (Radnoti Glass Technology Inc., Monrovia, CA) using KrebsHenseleit bicarbonate buffer that contained 4.75 $\mathrm{mg} / \mathrm{L}$ sodium taurocholate and $1.2 \mathrm{~g} / \mathrm{L}$ glucose. Livers were perfused at a flow rate of $30 \mathrm{~mL} / \mathrm{min}$ in a single-pass manner with a constant concentration $(0.1 \mu \mathrm{g} / \mathrm{mL})$ of $\mathrm{RH}-123$. The perfusate was continuously oxygenated with $95 \%$ oxygen and $5 \%$ carbon dioxide mixture, and the inlet perfusion pressure was monitored using a pressure transducer.

The viability of the liver was confirmed by monitoring the macroscopic appearance of the liver, relatively stable bile flow rates over the entire period of perfusion (60 min), wet liver weight of $<$ $4 \%$ of total body weight at the end of perfusion, low transaminase (ALT) levels in the outlet perfusate during the perfusion period ( 0 and $60 \mathrm{~min}$ ), and low and stable inlet pressure.

\section{Sample collection}

At the end of the 24 or $72 \mathrm{~h}$ of in vivo reperfusion period, blood was collected from the abdominal aorta into the heparinized syringes, and after centrifugation, plasma was separated and stored for the analysis of ALT.

For the liver perfusion experiments, inlet perfusate samples were drawn at 20,30, and $40 \mathrm{~min}$ after starting the constant infusion of RH-123. Additionally, outlet perfusate and bile samples were collected at $10 \mathrm{~min}$ intervals during the $60 \mathrm{~min}$ infusion of RH-123. At the end of the perfusion, livers were blotted dry and stored for further analysis. Perfusate, bile, and liver samples were stored at $-80^{\circ} \mathrm{C}$ for subsequent analysis of $\mathrm{RH}-123$, RH-110, and RH-Glu by high-performance liquid chromatography (HPLC).

\section{SAMPLE ANALYSIS}

Liver samples were homogenized in deionized water (1:9), and after an additional ten-fold dilution were used in the assay. The concentrations of RH123 and RH-110 in the liver homogenates, perfusate, and bile were analyzed by fluorescence HPLC both before and after treatment with $\beta$ glucuronidase, as described by us before (12). The concentrations of RH-Glu were then determined by subtracting the RH-123 concentrations in the unhydrolyzed samples from those in the corresponding hydrolyzed samples.
Perfusate and plasma concentrations of ALT were measured by spectrophotometry using a commercially available kit.

\section{Pharmacokinetic analysis}

The areas under the perfusate concentration-time curve from 0 to $60 \mathrm{~min}$ (AUC) for RH-123, RH110, and RH-Glu were calculated using linear trapezoidal method. RH-123 inlet concentrations $\left(\mathrm{C}_{\text {in }}\right)$ were calculated from the average of the three inlet samples drawn at 20,30, and $40 \mathrm{~min}$ of perfusion. The time-averaged hepatic availability of RH-123 during the 60-min perfusion period (F) was estimated using the following equation:

$$
F=\frac{X_{o u t}}{X_{\text {in }}}
$$

where $X_{\text {out }}$ and $X_{\text {in }}$ are the amount of RH-123 recovered in the perfusate from zero to $60 \mathrm{~min}$ and the total dose of RH-123 administered during the same period, respectively. $\mathrm{X}_{\text {out }}$ was estimated by multiplying the perfusate AUC of RH-123 by the perfusate flow (Q), which was $30 \mathrm{~mL} / \mathrm{min}$, and $\mathrm{X}_{\text {in }}$ was estimated by multiplying the $\mathrm{C}_{\text {in }}$ by the $\mathrm{Q}$ and duration of the perfusion $(60 \mathrm{~min})$. The timeaveraged hepatic extraction ratio (E) and hepatic clearance $\left(\mathrm{CL}_{\mathrm{h}}\right)$ of $\mathrm{RH}-123$ were then estimated using the following equations:

$$
\begin{aligned}
& E=1-F \\
& C L_{h}=Q \times E
\end{aligned}
$$

Biliary excretion rates of $\mathrm{RH}-123$ and $\mathrm{RH}-\mathrm{Glu}$ at any given time interval were determined by dividing the total amount of the drug or metabolite excreted into the bile during that interval by the length of the collection interval. The apparent biliary clearance $\left(\mathrm{CL}_{\text {bile,app }}\right)$ of $\mathrm{RH}-123$ or its generated metabolite RH-Glu were estimated by dividing the total amount of the drug or the metabolite excreted into the bile during the $60 \mathrm{~min}$ of perfusion by its respective perfusate AUC during the same period. Because of continuous accumulation and sequestration of RH-123 in the liver tissue during the constant infusion of RH-123 in IPRLs despite pseudo-steady state perfusate concentrations, the $\mathrm{CL}_{\text {bile,app }}$ of $\mathrm{RH}-123$ is expected to increase with an increase in the length of perfusion (12). Therefore, another parameter, 
termed biliary excretion index (BEI), was also calculated for RH-123 as shown in the following equation:

$$
\text { BEI }(\%)=\frac{D_{\text {bile }}}{D_{\text {liver }}} \times 100
$$

where $D_{\text {bile }}$ and $D_{\text {liver }}$ are the amounts of RH-123 recovered in the bile during the perfusion period and that recovered in the liver at the end of perfusion, respectively. This parameter is similar in concept to the BEI estimated in sandwich-cultured rat hepatocytes (22). In contrast to $\mathrm{CL}_{\text {bile,app, which }}$ normalizes the amount of RH-123 excreted in the bile by the extent of drug exposure in the perfusate, BEI normalizes the biliary excretion of the drug by the extent of its liver accumulation. Therefore, it is not expected to be dependent on the length of constant infusion of the drug in IPRLs.

\section{STATISTICAL ANALYSIS}

The effects of IR and time of reperfusion on different kinetic parameters were tested using twoway ANOVA followed by Bonferroni's post-hoc analysis of the means. Also, two-way ANOVA with repeated measures followed by Bonferroni's posthoc was used to compare the biliary excretion rates at different time points across the four treatment groups. In all the cases, $p<0.05$ was considered significant. All data are presented as mean \pm SD.

\section{RESULTS}

The plasma concentrations of ALT, as a marker of liver damage after IR, are shown in Figure 1. Whereas the plasma concentrations of ALT in the IR group were significantly $(p<0.001)$ higher than those in the Sham group $24 \mathrm{~h}$ after the in vivo reperfusion, similar concentrations of ALT were found in the IR and Sham groups at $72 \mathrm{~h}$ postreperfusion (Figure 1).

The outlet perfusate concentration-time profiles and associated pharmacokinetic parameters of RH123 and its metabolites are depicted in Figure 2 and Table 1, respectively. Except for the IR-24 group, the pseudo-steady-state outlet perfusate concentrations of RH-123 in all different groups were similarly low (3-5 ng/mL) (Fig 2A), resulting in extensive extraction ratios of $0.972-0.980$ and high $\mathrm{CL}_{\mathrm{h}}$ values close to the perfusion flow rate of $30 \mathrm{~mL} / \mathrm{min}$ (Table 1 ).

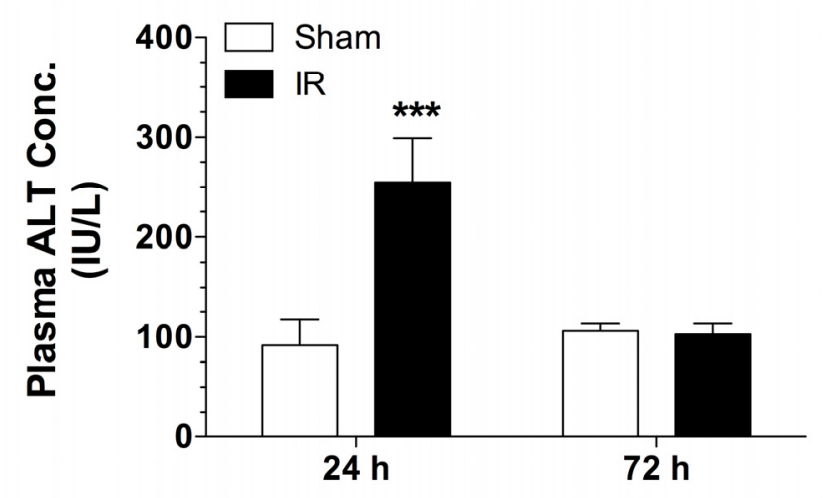

Figure 1. The plasma concentrations of alanine aminotransferase (ALT) following 24 or $72 \mathrm{~h}$ of reperfusion in rats subjected to $60 \mathrm{~min}$ of partial ischemia (IR) or sham operation (Sham). The columns and bars represent the mean and SD values, respectively. $* * * p<0.001$, significantly different from the respective Sham group based on two-way ANOVA, followed by Bonferroni's post-hoc analysis.

However, the outlet concentrations (Figure 2A) and AUC values (Table 1) for the IR-24 group were much higher $(p<0.001)$ than those of the Sham-24 group. In addition, the extraction ratio and $\mathrm{CL}_{\mathrm{h}}$ of RH-123 were significantly $(p<0.001)$ lower in this group (Table 1). Whereas the outlet concentrations and AUC values of the deacylated metabolite (RH110) were similar in all of the four groups (Figure 2B and Table 1), those of RH-Glu were significantly $(p<0.01)$ increased in the IR-24 group (Figure $2 \mathrm{C}$ and Table 1).

The biliary excretion rate-time profiles (A) and fraction of the dose recovered in the bile (B) are depicted in Figures 3 and 4 for the parent drug RH123 and the formed RH-Glu metabolite, respectively. The biliary excretion rates of $\mathrm{RH}-123$ and RH-Glu in the IR-24 group were significantly $(p<0.05$ or $<0.01)$ lower during some intervals, when compared with the rates at the corresponding times in the control group (Sham-24) (Figures 3A and 4A). Likewise, the biliary recoveries of RH-123 and RH-Glu in the IR-24 rats were reduced $(p<0.05)$ by $43 \%$ (Figure $3 \mathrm{~B}$ ) and $44 \%$ (Figure $4 \mathrm{~B}$ ), respectively. In contrast, both the biliary excretion rates and recoveries of RH-123 and RH-Glu in the IR-72 group were not different from those in the Sham-72 group (Figures 3 and 4). 
Table 1. Perfusate Pharmacokinetic Parameters of RH-123 and Its Main Metabolites RH-110 and RH-Glu in IPRL Preparations

\begin{tabular}{lccccc}
\hline \multirow{2}{*}{ Treatment } & \multicolumn{3}{c}{ AUC (ng.min/mL) } & \multicolumn{2}{c}{ RH-123 } \\
& RH-123 & RH-110 & RH-Glu & E & CL $_{\mathrm{h}}(\mathrm{mL} / \mathrm{min})$ \\
\hline Sham-24 & $112 \pm 95$ & $328 \pm 216$ & $44.6 \pm 37.5$ & $0.980 \pm 0.017$ & $29.4 \pm 0.5$ \\
IR-24 & $801 \pm 445^{* * *}$ & $240 \pm 50$ & $89.6 \pm 21.7^{* *}$ & $0.857 \pm 0.078^{* * *}$ & $25.7 \pm 2.3^{* * *}$ \\
Sham-72 & $117 \pm 49$ & $308 \pm 39$ & $57.2 \pm 17.9$ & $0.979 \pm 0.009$ & $29.4 \pm 0.3$ \\
IR-72 & $160 \pm 55$ & $291 \pm 16$ & $37.5 \pm 10.9$ & $0.972 \pm 0.009$ & $29.1 \pm 0.3$ \\
\hline
\end{tabular}

Livers were collected from rats subjected to $1 \mathrm{~h}$ of partial hepatic ischemia (IR) or sham operation (Sham), followed by 24 or $72 \mathrm{~h}$ of in vivo reperfusion and perfused ex vivo with a constant concentration $(100 \mathrm{ng} / \mathrm{mL})$ of RH-123 for 60 min.Data are presented as mean $\pm \mathrm{SD} . * * p<0.01$ and $* * * p<0.001$, significantly different from the corresponding Sham group (two-way ANOVA followed by Bonferroni's post-hoc analysis).
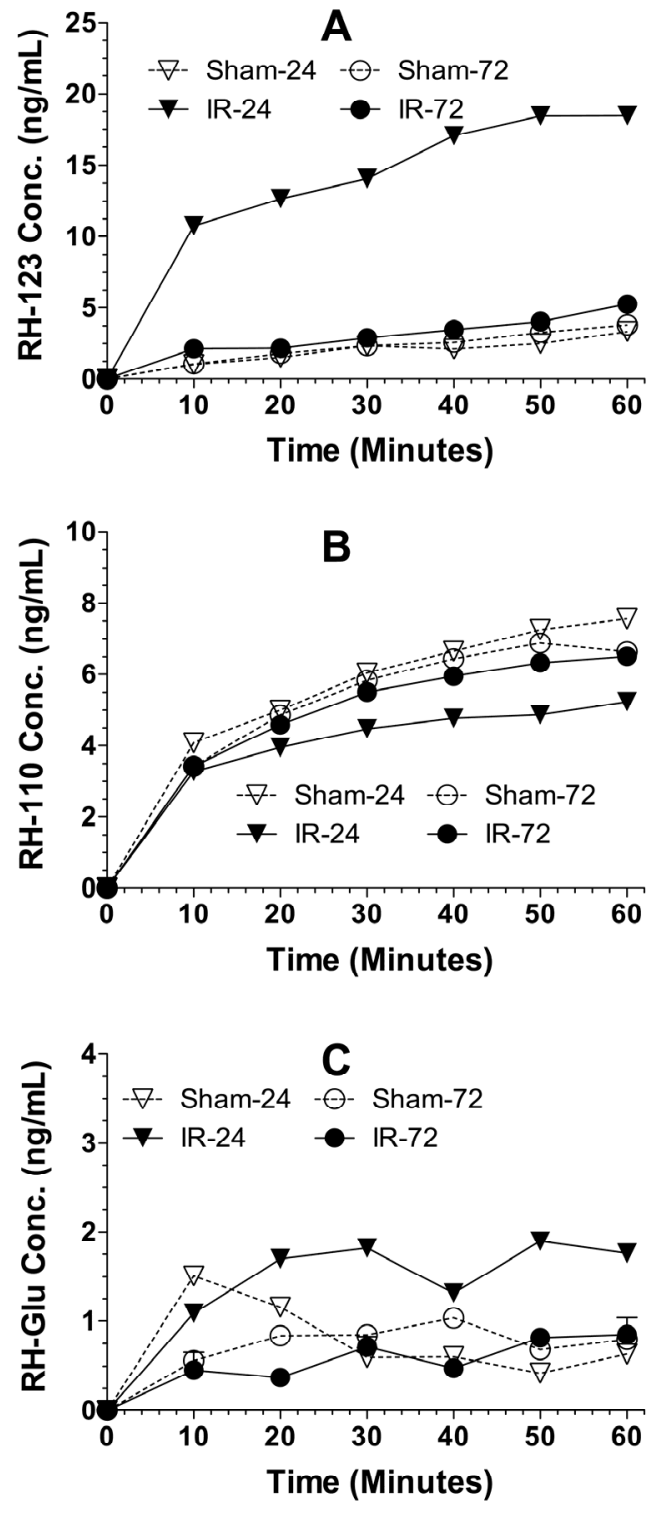

Figure 2. The outlet perfusate concentration-time profiles of RH-123 (A), RH-110 (B), and RH-Glu (C) in isolated livers perfused with a constant inlet concentration of $100 \mathrm{ng} / \mathrm{mL}$ of RH-123 for $60 \mathrm{~min}$. Livers were collected from rats subjected to $1 \mathrm{~h}$ of partial hepatic ischemia (IR) or sham operation (Sham), followed by 24 or $72 \mathrm{~h}$ of in vivo reperfusion. Mean values are shown without SD bars for clarity.
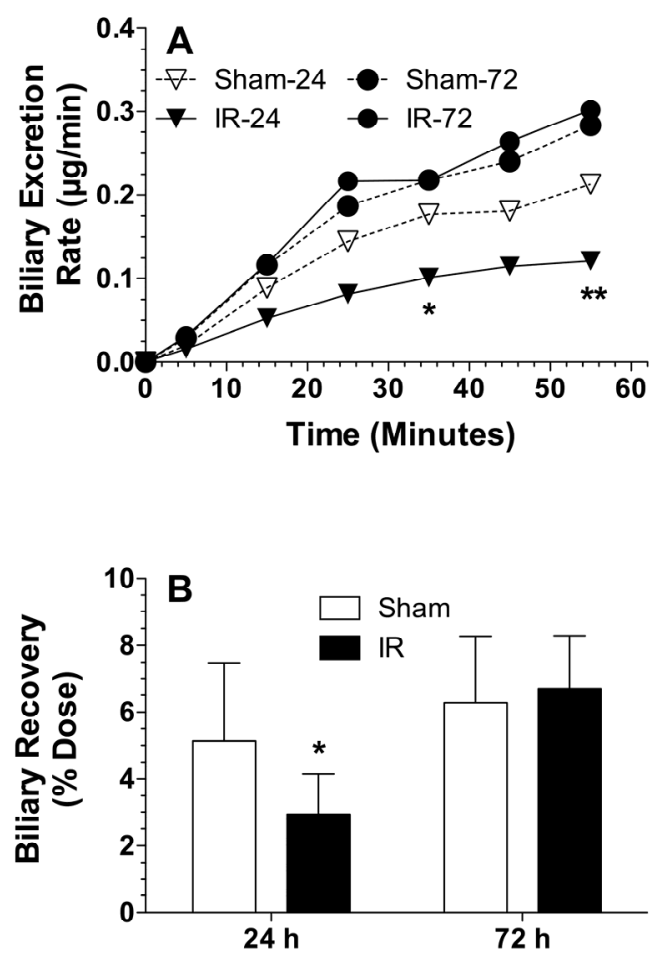

Figure 3. The biliary excretion rate-time profiles (A) and cumulative biliary excretion (B) of RH-123 in isolated livers perfused with a constant inlet concentration of 100 $\mathrm{ng} / \mathrm{mL}$ of RH-123 for $60 \mathrm{~min}$. Livers were collected from rats subjected to $1 \mathrm{~h}$ of partial hepatic ischemia (IR) or sham operation (Sham), followed by 24 or $72 \mathrm{~h}$ of in vivo reperfusion. The symbols or columns represent the mean values and bars represent the SD values. $* p<0.05$ and $* *$ $p<0.01$, significantly different from the respective Sham group based on repeated measure (A) or regular (B) twoway ANOVA, followed by Bonferroni's post-hoc analysis. 

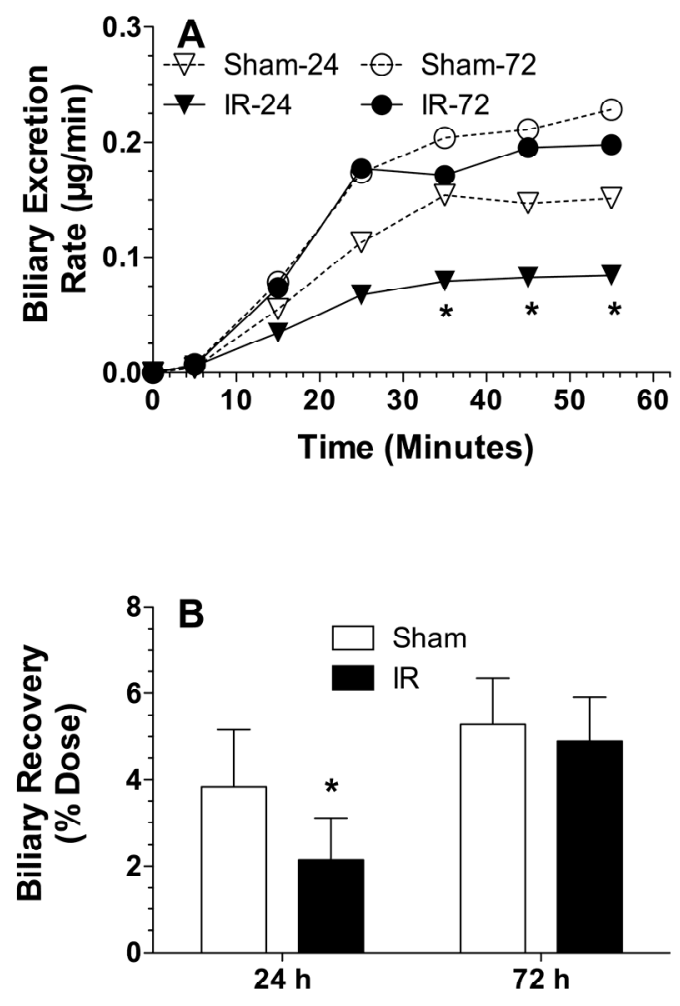

Figure 4. The biliary excretion rate-time profiles (A) and cumulative biliary excretion (B) of RH-Glu in isolated livers perfused with a constant inlet concentration of 100 $\mathrm{ng} / \mathrm{mL}$ of RH-123 for $60 \mathrm{~min}$. Livers were collected from rats subjected to $1 \mathrm{~h}$ of partial hepatic ischemia (IR) or sham operation (Sham), followed by 24 or $72 \mathrm{~h}$ of in vivo reperfusion. The symbols or columns represent the mean values and bars represent the SD values. ${ }^{*} p<0.05$, significantly different from the respective Sham group based on repeated measure (A) or regular (B) two-way ANOVA, followed by Bonferroni's post-hoc analysis.

The apparent biliary clearance (A) and BEI (B) of $\mathrm{RH}-123$ and $\mathrm{CL}_{\text {bile,app }}$ of $\mathrm{RH}-\mathrm{Glu}$ (C) are presented in Figure 5. The BEI values could not be estimated for RH-Glu because, in agreement with a previous report (12), no RH-Glu was detected in the liver. Both $\mathrm{CL}_{\text {bile,app }}$ (Figure 5A) and BEI (Figure $5 \mathrm{~B})$ values of $\mathrm{RH}-123$ in the IR-24 group were substantially lower than the corresponding values in the Sham-24 group. However, the extent of reduction in the $\mathrm{CL}_{\text {bile,app }}$ value $(92 \%, p<0.001)$ was more than that observed in the BEI value $(50 \%)$. The $\mathrm{CL}_{\text {bile,app }}$ value of $\mathrm{RH}-\mathrm{Glu}$ was also reduced $(p<0.01)$ by $83 \%$ as a result of IR injury in the 24 h-reperfusion group (Figure $5 \mathrm{C}$ ). Similar to other kinetic parameters, no differences were observed between the IR-72 and Sham-72 groups in their $\mathrm{CL}_{\text {bile,app }}$ and BEI values (Figure 5).
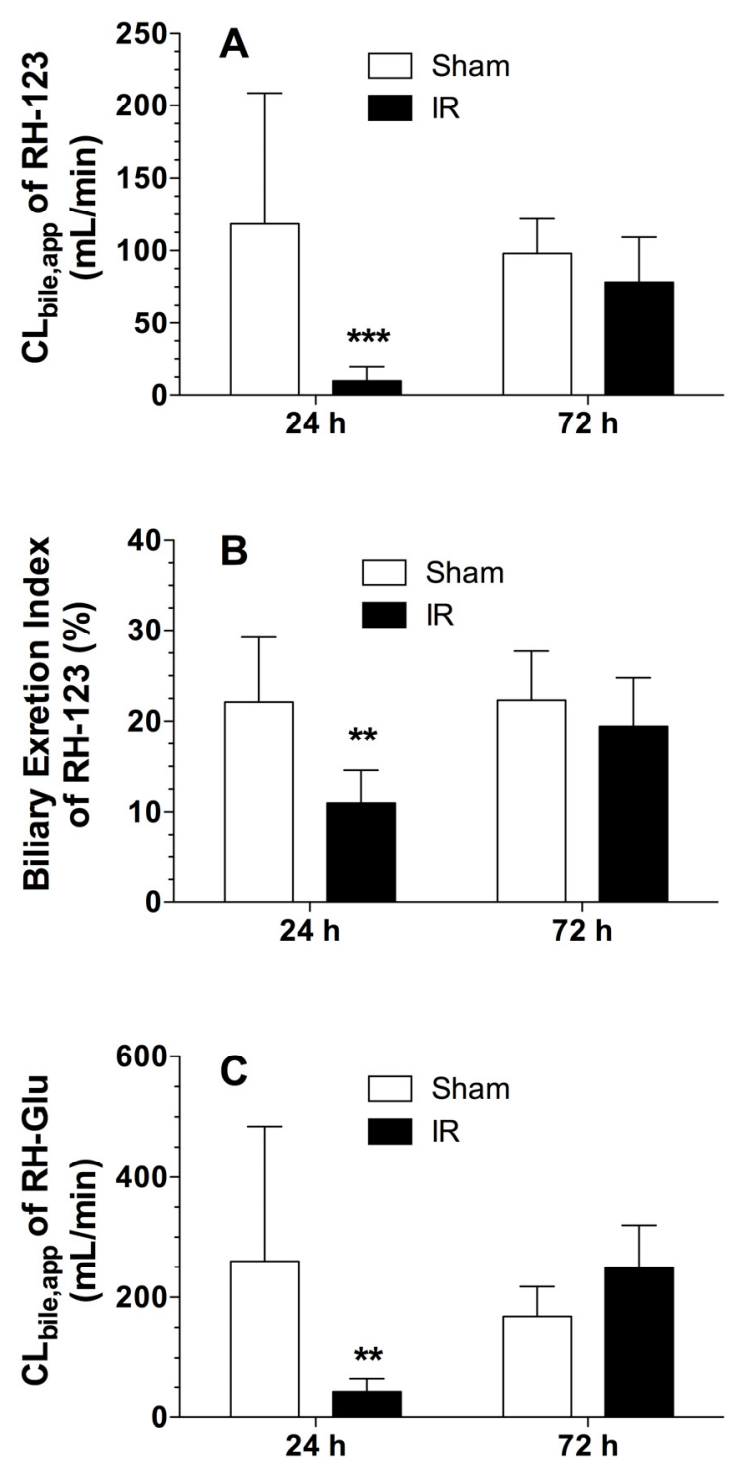

Figure 5. The apparent biliary clearance (A) and biliary excretion index (B) of RH-123 and apparent biliary clearance of RH-Glu (C) in isolated livers perfused with a constant inlet concentration of $100 \mathrm{ng} / \mathrm{mL}$ of RH-123 for $60 \mathrm{~min}$. Livers were collected from rats subjected to 1 $\mathrm{h}$ of partial hepatic ischemia (IR) or sham operation (Sham), followed by 24 or $72 \mathrm{~h}$ of in vivo reperfusion. The columns and bars represent the mean and SD values, respectively. ${ }^{* *} p<0.01$ and $* * * p<0.001$, significantly different from the respective Sham group based on twoway ANOVA, followed by Bonferroni's post-hoc analysis. 
The mass balance data for RH-123 (A), RH-Glu (B), RH-110 (C), and total drug/metabolites (D) are presented in Figure 6. The major moiety recovered was the parent drug (Figure 3A), which was present in the perfusate, bile, and the liver tissue, with the highest recovery (26-35\% of the dose) in the liver tissue. RH-Glu was present in the perfusate and bile only, and RH-110 was present in the perfusate and liver tissue only. Neither IR-24 nor IR-72 had any significant effect on the overall recovery of RH-123 (Figure 6A), RH-Glu (Figure 6B), or RH-110 (Figure 6C) or the total mass balance (Figure 6D).
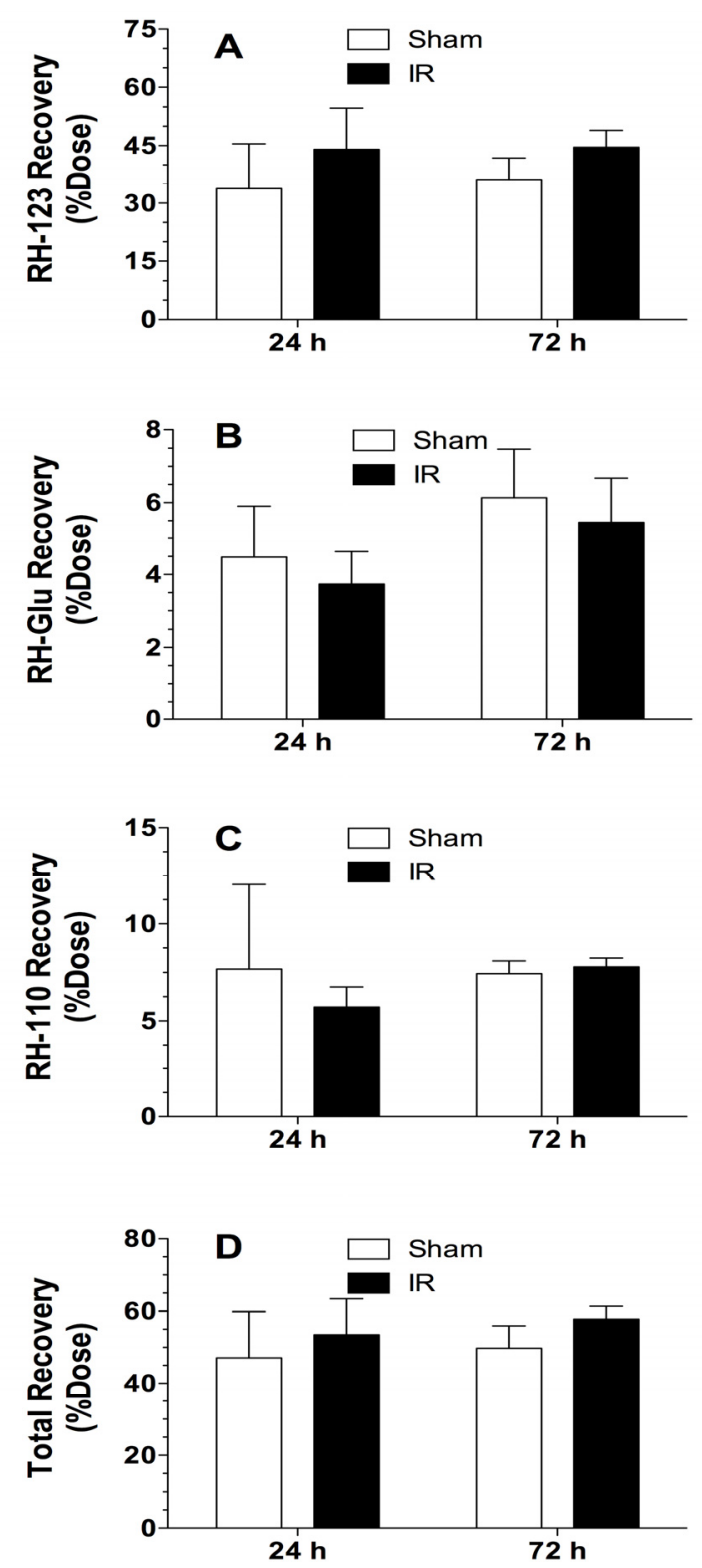

Figure 6. The mass balance data for RH-123 (A), RHGlu (B), RH-110 (C), and total drug/metabolites (D) in isolated livers perfused with a constant inlet concentration of $100 \mathrm{ng} / \mathrm{mL}$ of $\mathrm{RH}-123$ for $60 \mathrm{~min}$. Livers were collected from rats subjected to $1 \mathrm{~h}$ of partial hepatic ischemia (IR) or sham operation (Sham), followed by 24 or $72 \mathrm{~h}$ of in vivo reperfusion. The columns and bars represent the mean and SD values, respectively.

The bile flow rates for individual intervals and the average bile flow rates during the entire $60 \mathrm{~min}$ perfusion of livers are presented in Figure 7. Whereas the bile flow rates at the later intervals were significantly $(p<0.05)$ lower for the IR-24 group, relative to the values for the Sham-24 group (Figure 7A), there was no difference in the flow rates between the $72 \mathrm{~h}$ reperfusion groups (Figure 7B). In agreement with the individual interval data (Figures 7A and B), the average flow rate for the IR-24 group was $23 \%$ lower $(p<0.05)$ than that in the Sham-24 group (Figure 7C).

\section{DISCUSSION}

Recent reports $(7,8,10)$ have shown that partial liver IR injury significantly alters the gene expression of Mrp2 and Mdr1b (P-gp) in the liver of rats. Because these two transporters play a major role in the biliary excretion of a number of drugs, the pharmacokinetics of these drugs may be significantly altered after the IR injury. In the present study, we used an IPRL model to investigate the effect of warm hepatic IR injury on the hepatobiliary disposition of RH-123, which is a dual marker of P-gp and Mrp2 function. Warm hepatic IR injury significantly altered the hepatobiliary disposition of RH-123, which is a Pgp marker, and its glucuronidated metabolite, which is excreted into the bile by Mrp2 (Figures 3-5). Both biliary excretion and biliary clearance (or BEI) of RH-123 and RH-Glu were significantly reduced after hepatic ischemia followed by $24 \mathrm{~h}$ of reperfusion. However, both of these parameters returned to normal levels after $72 \mathrm{~h}$ of reperfusion (Figures 3-5). These data suggest substantial decreases in the functional activity of both P-gp and Mrp2 transporters $24 \mathrm{~h}$ following the IR injury. 

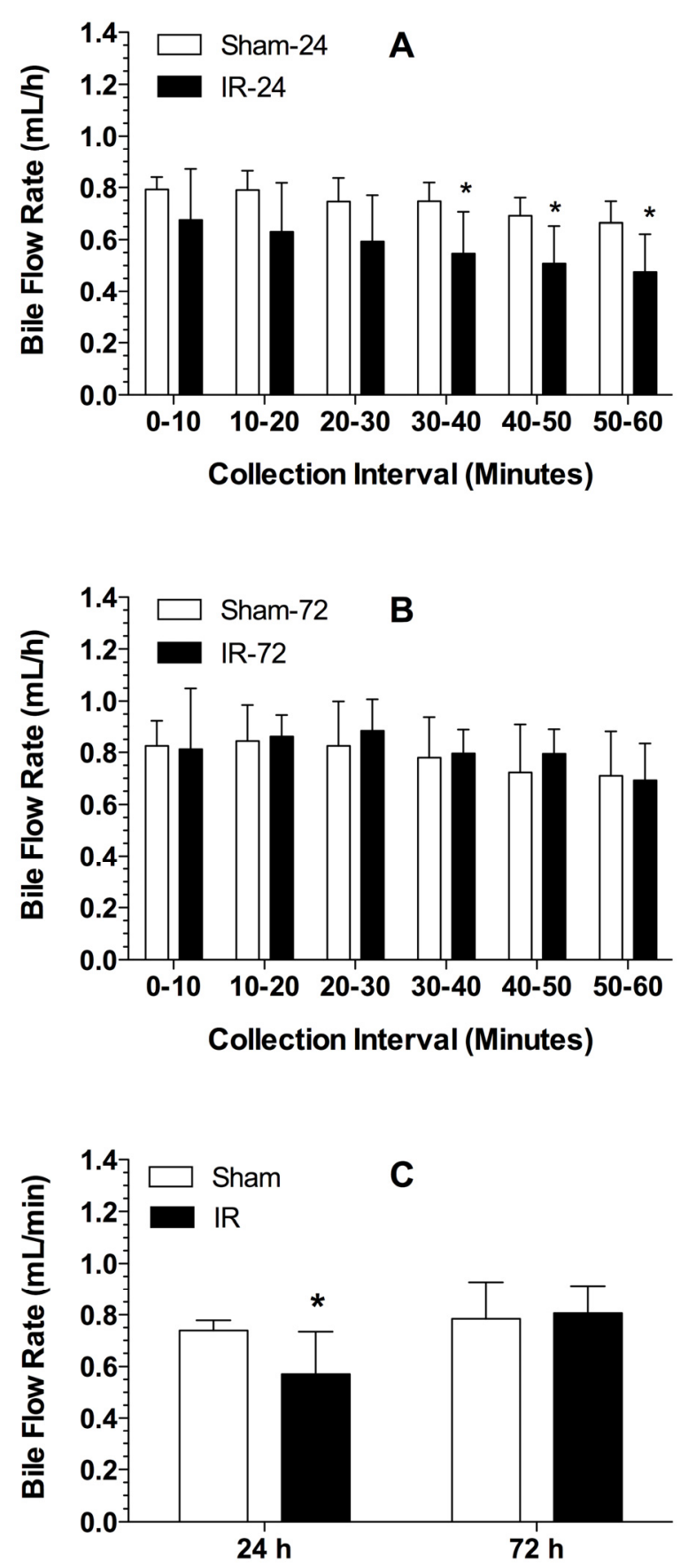

Figure 7. The 10-min interval bile flow rates for the 24 (A) and 72 (B) $\mathrm{h}$ reperfusion groups and the average bile flow rates during the entire $60 \mathrm{~min}$ of ex vivo perfusion (C) in isolated livers. Livers were collected from rats subjected to $1 \mathrm{~h}$ of partial hepatic ischemia (IR) or sham operation (Sham), followed by 24 or $72 \mathrm{~h}$ of in vivo reperfusion. The columns and bars represent the mean and SD values, respectively. ${ }^{*} p<0.05$, significantly different from the respective Sham group based on repeated measure (A and $\mathrm{B}$ ) or regular (C) two-way ANOVA, followed by Bonferroni's post-hoc analysis.
The decrease in the biliary excretion (Figure 4) and $\mathrm{CL}_{\text {bile,app }}$ (Figure 5C) of the generated RH-Glu, observed in our studies, is in agreement with the reported $(8-10,23)$ downregulation of the mRNA and protein levels of this transporter as a result of hepatic IR injury.

In a partial IR model in rats identical to ours, Tanaka et al. $(8,10)$ showed that the hepatic IR injury caused a significant reduction in the Mrp2 mRNA in the liver tissue following $60 \mathrm{~min}$ of ischemia and $24 \mathrm{~h}$ of reperfusion. However, the mRNA levels returned to normal values after $48 \mathrm{~h}$ of reperfusion. The decrease in the mRNA levels at $24 \mathrm{~h}(8,10)$ was accompanied by 88 and $80 \%$ reductions in the Mrp2 protein expression after 24 and $48 \mathrm{~h}$ of reperfusion, respectively (8). However, the downregulation of the protein expression was more extensive than that of mRNA, suggesting additional post-transcriptional downregulation of Mrp2 by IR (8). Our observation that the hepatic IR decreases the $\mathrm{CL}_{\text {bile,app }}$ of RH-Glu, a substrate of Mrp2, by $83 \%$ after $24 \mathrm{~h}$ of reperfusion (Figure 5 C) is in close agreement with the findings of Tanaka et al. Furthermore, our data suggest that this effect is abolished $72 \mathrm{~h}$ following the reperfusion (Figure 5C).

In addition to a reduced transport function for Mrp2, our studies also revealed a substantial IRinduced reduction in the activity of P-gp, as demonstrated by 92 and $50 \%$ reductions in the $\mathrm{CL}_{\text {bile,app }}$ (Figure 5A) and BEI (Figure 5B) of RH123 , respectively. The reduction in the transport activity of P-gp, however, does not correlate with the limited data available on the effects of hepatic IR on the Mdr1b mRNA (10) or P-gp protein expression (7) reported before. Significant increases $(\geq 50 \%$ ) in the Mdr1b mRNA was reported 6, 24, and $48 \mathrm{~h}$ following reperfusion of rat livers (10). Additionally, we are aware of one study (7) that showed a modest $(\sim 20 \%)$, but statistically significant, increase in the P-gp protein expression in the liver of rats $12 \mathrm{~h}$ following reperfusion. The lack of correlation between the P-gp expression and functional activity, which has also been reported by others $(11,24)$, may be due to several reasons. One likely mechanism is that changes in the energy status of the liver may be responsible for the decreased activity of P-gp, an ATP binding cassette transporter protein. Liver ATP concentrations, which substantially decrease during the ischemic period, gradually recover during the reperfusion of 
the liver $(25,26)$. Our attempts to accurately measure the ATP concentrations in our IPRLs at the end of the perfusion were unsuccessful because of the extremely rapid and variable degradation of ATP during the period between the end of perfusion and preparation of the livers for the storage at $-80^{\circ} \mathrm{C}$. However, using an IR model identical to ours (60 min of partial ischemia in rats), Ofluoglu et al. (27) reported that after $24 \mathrm{~h}$ of reperfusion, the hepatic concentrations of ATP were $\sim 30 \%$ lower than that of sham-operated animals. Therefore, a decrease in the liver ATP concentrations might have superseded the modest increase reported (7) in the protein levels of P-gp, explaining the lower Pgp activity observed in our IR-24 group.

Another possible reason for the apparent lack of correlation between the P-gp protein and function after hepatic IR may be related to the intracellular trafficking of P-gp after the injury. The reported (7) IR-induced increase in the P-gp expression was based on Western blot analysis, which is a measure of total tissue P-gp. However, it is possible that P$\mathrm{gp}$ is retrieved from the bile canalicular membranes into intrahepatic sites in the IR-24 livers. Indeed, it has been reported $(28,29)$ that various factors, such as the concentrations of cAMP, taurocholate, $\mathrm{Ca}^{++}$, or ATP, which may potentially be altered after IR injury, may affect the distribution of P-gp between the canalicular membranes and intracellular sites at the canalicular membrane.

It has been reported (30) that the uptake of RH123 in sandwich cultured rat hepatocytes consists of both linear and saturable components, with Oatp1a4 as the likely carrier for the latter. Therefore, it may be argued that an IR-induced decrease in the uptake of $\mathrm{RH}-123$ into the liver might have led to a decrease in its biliary excretion. The possibility of an IR effect on the influx transporters cannot be ruled out based on our data. However, such an effect, if indeed exists, cannot by itself explain our biliary excretion data for RH-123 (Figures 5A and B). Whereas a possible reduction in the uptake of RH-123 may cause a reduction in $\mathrm{CL}_{\text {bile,app }}$ (Figure $5 \mathrm{~A}$ ), it cannot explain the reduction observed in the BEI value (Figure 5B). This is because $\mathrm{CL}_{\text {bile,app }}$ is estimated by dividing the rate (or amount) of the drug excreted into the bile by its corresponding perfusate concentration (or AUC). Therefore, a reduction in the uptake, causing an increase in the perfusate exposure to drug, will be reflected as a

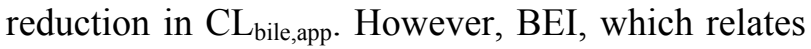

the biliary excretion of the drug to its accumulation in the liver (equation 4), instead of the perfusate, is only a reflection of the efflux (from the liver to bile) and not the uptake (from the perfusate to the liver) of the drug. Indeed, the much higher magnitude of reduction $(92 \%)$ in $\mathrm{CL}_{\text {bile,app }}$ (Figure 5A), compared with the $50 \%$ reduction in BEI (Figure 5B), as a results of IR-24, might have been due to additional effects of IR-24 on the uptake of RH-123, which could only be reflected in $\mathrm{CL}_{\text {bile,app }}$ and not BEI.

Our suggestion that IR-24 decreases the transport function of Mrp2 is based on the IRinduced reduction in the $\mathrm{CL}_{\text {bile,app }}$ of $\mathrm{RH}-\mathrm{Glu}$ generated after the administration of RH-123. Therefore, it may be argued that the biliary excretion of RH-Glu might have been influenced by potential changes in the formation of the metabolite as a result of IR. However, the fact that the mass balance data for the conjugated metabolite was not affected by IR (Figure 6B) suggests that IR does not affect the glucuronidation of RH-123. Nevertheless, future studies using direct administration of Mrp2 substrates are needed to confirm the results presented here using the formed metabolite RHGlu.

In addition to the no change in the extent of glucuronidation of RH-123 (Figure 5B), mass balance data also suggest that the hepatic IR injury does not have any effect on the formation of RH110 in our model at 24 or $72 \mathrm{~h}$ after the reperfusion (Figure 6C). Recently (18), we showed a significant reduction in the cytochrome $\mathrm{P} 450$ reductase and cytochrome P450 2E1-mediated metabolism of chlorzoxazone $3 \mathrm{~h}$ following reperfusion of the ischemic livers. However, the effect of IR on the P450-mediated metabolism was absent at $24 \mathrm{~h}$ following reperfusion. The lack of the effect of IR24 or IR-72 on the deacylation of RH-123 to RH110 , observed here, is similar to the absence of the effects of IR on cytochrome P450 reductase and cytochrome P450 2E1 metabolism of chlorzoxazone at $24 \mathrm{~h}$ following reperfusion.

In conclusion, warm hepatic IR injury reduces the activities of both P-gp and Mrp2 in the rat liver $24 \mathrm{~h}$ after reperfusion of livers subjected to $60 \mathrm{~min}$ of partial ischemia. However, the functions of these transporters return to normal levels $72 \mathrm{~h}$ after reperfusion. If extrapolated to humans, these findings may have clinical ramifications for Mrp2 and P-gp substrate drugs that are administered during the first $24 \mathrm{~h}$ after the ischemic insult to the 
liver. Further studies, including in vivo and mechanistic experiments, are needed to determine the effects of liver IR injury on the extent of alterations in the overall pharmacokinetics and pharmacodynamics of drugs whose elimination is dependent on their excretion into the bile.

\section{ACKNOWLEDGMENTS}

This research was financially supported by the Vascular Drug Research Center at the Texas Tech School of Pharmacy.

\section{REFERENCES}

1. Kupiec-Weglinski JW, Busuttil RW. Ischemia and reperfusion injury in liver transplantation. Transplant. Proc. 2005; 37: 1653-1656.

2. Serracino-Inglott F, Habib NA, Mathie RT. Hepatic ischemia-reperfusion injury. Am. J. Surg. 2001; 181: 160-166.

3. Vedder NB, Fouty BW, Winn RK, Harlan JM, Rice CL. Role of neutrophils in generalized reperfusion injury associated with resuscitation from shock. Surgery 1989; 106: 509-516.

4. Lichtman SN, Lemasters JJ. Role of cytokines and cytokine-producing cells in reperfusion injury to the liver. Semin. Liver Dis. 1999; 19: 171-187.

5. Fardel O, Le Vee M. Regulation of human hepatic drug transporter expression by pro-inflammatory cytokines. Expert Opin. Drug Metab. Toxicol. 2009; 5: 1469-1481.

6. Piquette-Miller $\mathrm{M}$, Pak A, Kim H, Anari R, Shahzamani A. Decreased expression and activity of P-glycoprotein in rat liver during acute inflammation. Pharm Res 1998; 15: 706-711.

7. Ikemura K, Urano K, Matsuda H, Mizutani H, Iwamoto T, Okuda M. Decreased oral absorption of cyclosporine A after liver ischemia-reperfusion injury in rats: The contribution of CYP3A and Pglycoprotein to the first-pass metabolism in intestinal epithelial cells. J. Pharmacol. Exp. Ther. 2009; 328: 249-255.

8. Tanaka Y, Chen C, Maher JM, Klaassen CD. Ischemia-reperfusion of rat livers decreases liver and increases kidney multidrug resistance associated protein 2 (Mrp2). Toxicological Sciences 2008; 101: 171-178.

9. Fouassier L, Beaussier M, Schiffer E, Rey C, Barbu V, Mergey M, Wendum D, Callard P, Scoazec JY, Lasnier E, Stieger B, Lienhart A, Housset C. Hypoxia-induced changes in the expression of rat hepatobiliary transporter genes. Am. J. Physiol. Gastrointest. Liver Physiol. 2007; 293: G25-35.
10. Tanaka Y, Chen C, Maher JM, Klaassen CD. Kupffer cell-mediated downregulation of hepatic transporter expression in rat hepatic ischemiareperfusion. Transplantation 2006; 82: 258-266.

11. Micuda S, Brcakova E, Fuksa L, Cermanova J, Osterreicher J, Hroch M, Mokry J, Pejchal J, Martinkova J, Staud F. P-glycoprotein function and expression during obstructive cholestasis in rats. Eur. J. Gastroenterol. Hepatol. 2008; 20: 404-412.

12. Parasrampuria R, Mehvar R. Hepatobiliary disposition of rhodamine 123 in isolated perfused rat livers. Xenobiotica 2008; 38: 1263-1273.

13. Parasrampuria R, Mehvar R. Effects of Pglycoprotein and Mrp2 inhibitors on the hepatobiliary disposition of Rhodamine 123 and its glucuronidated metabolite in isolated perfused rat livers. J. Pharm. Sci. 2010; 99: 455-466.

14. Patel S, Pachter HL, Yee H, Schwartz JD, Marcus SG, Shamamian P. Topical hepatic hypothermia attenuates pulmonary injury after hepatic ischemia and reperfusion. J. Am. Coll. Surg. 2000; 191: 650656.

15. Weinbroum AA, Hochhauser E, Rudick V, Kluger Y, Sorkine P, Karchevsky E, Graf E, Boher P, Flaishon R, Fjodorov D, Niv D, Vidne BA. Direct induction of acute lung and myocardial dysfunction by liver ischemia and reperfusion. J Trauma 1997; 43: 627-633; discussion 633-625.

16. Lee HT, Park SW, Kim M, D'Agati VD. Acute kidney injury after hepatic ischemia and reperfusion injury in mice. Lab. Invest. 2009; 89: 196-208.

17. Behrends M, Hirose R, Park YH, Tan V, Dang K, Xu F, Park SH, Niemann CU. Remote renal injury following partial hepatic ischemia/reperfusion injury in rats. J. Gastrointest. Surg. 2008; 12: 490-495.

18. Shaik IH, Mehvar R. Effects of normothermic hepatic ischemia-reperfusion injury on the in vivo, isolated perfused liver, and microsomal disposition of chlorzoxazone, a cytochrome $\mathrm{P} 450$ 2E1 probe, in rats. J. Pharm. Sci. 2011; 100: 5281-5292.

19. Shaik IH, Mehvar R. Cytochrome P450 induction by phenobarbital exacerbates warm hepatic ischemiareperfusion injury in rat livers. Free Radic. Res. 2010; 44: 441-453.

20. Mehvar R, Zhang XP. Development and application of an isolated perfused rat liver model to study the stimulation and inhibition of tumor necrosis factoralpha production ex vivo. Pharm. Res. 2002; 19: 47-53.

21. Mehvar R, Chimalakonda AP. Hepatic disposition of cyclosporine $\mathrm{A}$ in isolated perfused rat livers. $\mathrm{J}$. Pharm. Pharm. Sci. 2004; 7: 47-54.

22. Liu X, Chism JP, LeCluyse EL, Brouwer KR, Brouwer KL. Correlation of biliary excretion in sandwich-cultured rat hepatocytes and in vivo in rats. Drug Metab. Dispos. 1999; 27: 637-644. 
23. Ban D, Kudo A, Sui S, Tanaka S, Nakamura N, Ito K, Suematsu M, Arii S. Decreased Mrp2-dependent bile flow in the post-warm ischemic rat liver. J. Surg. Res. 2009; 153: 310-316.

24. Meaden ER, Hoggard PG, Khoo SH, Back DJ. Determination of P-gp and MRP1 expression and function in peripheral blood mononuclear cells in vivo. J. Immunol. Methods 2002; 262: 159-165.

25. Bedirli N, Ofluoglu E, Kerem M, Utebey G, Alper M, Yilmazer D, Bedirli A, Ozlu O, Pasaoglu H. Hepatic energy metabolism and the differential protective effects of sevoflurane and isoflurane anesthesia in a rat hepatic ischemia-reperfusion injury model. Anesth. Analg. 2008; 106: 830-837.

26. Lee WY, Lee SM. Synergistic protective effect of ischemic preconditioning and allopurinol on ischemia/reperfusion injury in rat liver. Biochem. Biophys. Res. Commun. 2006; 349: 1087-1093.
27. Ofluoglu E, Kerem M, Pasaoglu H, Turkozkan N, Seven I, Bedirli A, Utku Yilmaz T. Delayed energy protection of ischemic preconditioning on hepatic ischemia/reperfusion injury in rats. Eur. Surg. Res. 2006; 38: 114-121.

28. Kipp H, Arias IM. Intracellular trafficking and regulation of canalicular ATP-binding cassette transporters. Semin. Liver Dis. 2000; 20: 339-351.

29. Kipp H, Pichetshote N, Arias IM. Transporters on demand: intrahepatic pools of canalicular ATP binding cassette transporters in rat liver. J. Biol. Chem. 2001; 276: 7218-7224.

30. Annaert PP, Brouwer KL. Assessment of drug interactions in hepatobiliary transport using rhodamine 123 in sandwich-cultured rat hepatocytes. Drug Metab. Dispos. 2005; 33: 388-394. 